\title{
Construction of Indoor Thermal Comfort Environmental Monitoring System Based on the IoT Architecture
}

\author{
Wen-Tsai Sung $\mathbb{D}^{1},{ }^{1}$ Sung-Jung Hsiao $\mathbb{D}^{2},{ }^{2}$ and Jing-An Shih ${ }^{1}$ \\ ${ }^{1}$ Department of Electrical Engineering, National Chin-Yi University of Technology, No. 57, Sec. 2, Zhongshan Rd., \\ Taiping Dist., Taichung 41170, Taiwan \\ ${ }^{2}$ Department of Computer Science and Information Engineering, Hungkuo Delin University of Technology, Taiwan
}

Correspondence should be addressed to Sung-Jung Hsiao; topdike@gmail.com

Received 18 March 2019; Revised 7 May 2019; Accepted 15 May 2019; Published 11 July 2019

Academic Editor: Jaime Lloret

Copyright (C) 2019 Wen-Tsai Sung et al. This is an open access article distributed under the Creative Commons Attribution License, which permits unrestricted use, distribution, and reproduction in any medium, provided the original work is properly cited.

\begin{abstract}
With the development and progress of technology, people's requirements for living quality are increasingly higher. This study builds an indoor thermal comfort environmental monitoring system through the Internet of Things (IoT) architecture to explore the thermal comfort of people in indoor environments. Then, the applicable indicators are selected from a series of thermal comfort pointers, and the controllable indoor environmental parameters are analyzed and simulated on MATLAB to obtain the impact on the thermal comfort indicators, which can serve as important data to set up the fuzzy rule base. Next, according to the ISO7730 comfort standard and energy saving, three ways to control thermal comfort are proposed. With Arduino UNO as the development substrate, the sensing nodes for the indoor environment are set up, and the wireless sensing network is configured with ESP8266 to transmit the sensing data to the terminal. Monitored by the C\# human-machine interface, the controllable load is controlled by wireless remote mode. Finally, the data is stored in the database for follow-up experimentation and analysis. Through actual measurement experiments, the thermal comfort and energy saving effects, under comfort, general, and energy-saving modes, as proposed in this study, are verified to achieve a balance between thermal comfort and energy saving.
\end{abstract}

\section{Introduction}

This study mainly explores the thermal comfort of people in indoor environments under the Internet of Things (IoT) architecture [1]. The suitable indicators for this study are selected from a series of thermal comfort pointers. After comparison and selection, this study uses the Predicted Mean Vote (PMV), which considers the most comprehensive influencing factors for human thermal comfort and is also the most common indoor thermal comfort assessment indicator. There are six main reference parameters for PMV: Ambient temperature, average radiant temperature, relative humidity, indoor wind speed, clothing resistance, and metabolic rate [2-4].

The controllable indoor environment parameters are analyzed and simulated on MATLAB, and the influences of three controllable parameters, ambient temperature, relative humidity, and indoor wind speed on the PMV, are obtained. Then, the data is used as the setting basis for the fuzzy control logic rule base, in order to control the load and provide the people in the room with relatively better thermal comfort and relatively better energy efficiency $[5,6]$.

The human-machine monitoring interface is designed on the main control PC using Visual Studio C\# software, and the control mode proposed in this study can be selected on the interface to control the parameters of temperature, humidity, and wind speed. The other parameters are actual values, which are measured on multiple nodes in an indoor environment. Then, the data in each area of the room is analyzed, and the nodes are equipped with temperature, humidity, wind speed, carbon dioxide, and fine aerosol sensors. When the sensors measure the data, the data is processed and integrated by Arduino UNO as the development substrate. It is transmitted to a PC through Wi-Fi via ESP8266, and the thermal comfort pointers are calculated according to the data and displayed on the human-machine monitoring interface. The ambient temperature, relative humidity, and indoor wind speed monitoring data will be used in the fuzzy thermal 
comfort intelligent control and provide people in the room with a relatively better thermal comfort experience under relatively better energy efficiency. The fine aerosol and carbon dioxide concentration thresholds are set by the system, which will automatically turn on the air cleaner or beep and display a warning window. Therefore, other seasonal climate changes, the parameters of Clothing resistance, and load control, such as heating from electric heaters, may be added to improve the overall thermal comfort control system.

In an experiment under the energy-saving mode, the desired effect cannot be realized perfectly due to the load limitation. Therefore, the cold air load may be improved in the future, and even the fan load may be controlled by PWM to accord with the control requirements of thermal comfort, which will ensure both physical comfort and energy saving [7-9].

In the future, air quality indicators (AQI), such as carbon monoxide, ozone, sulfur dioxide, and nitrogen dioxide, can be added to consider their influence on human health. Finally, the ultimate purpose of this study is to establish a comfort monitoring system that considers all indoor factors, makes users feel more comfortable, and features energy-saving and healthier life.

This paper is organized as follows. Section 1 is the introduction, which states the research background, research purposes, and research methods of this paper. Section 1 also includes the related literature review, which explains the concept and technology development of the IoT, discusses the thermal comfort assessment methods and related literature of this study, and describes the relevant literature and knowledge used in this study. Section 2 introduces the system architecture and hardware equipment and describes the system architecture in this study, as well as the related hardware equipment and sensors used in the experiment. Section 3 illustrates the research experiment and simulation, demonstrates the influences of various factors on the thermal comfort assessment method, and describes the fuzzy control settings and experimental results; Section 4 includes the conclusions, which summarize the research results and the future research direction.

In the era of today of the rapid development of airconditioning systems, the control of the system is quite mature. The development of the controller, from the most typical constant temperature control, slowly developed to the controller that developed based on the algorithm...etc. In addition to the innovative control methods, it is able to achieve indoor comfort requirements while saving energy. As a goal, the control of indoor comfort demand is the cold and hot feeling of the human body to the environment. As a guideline for control, many scholars have explored and proposed comfort indicators.

The Predicted Mean Vote (PMV) is a human body heat balance model published by the Danish scholar Professor P.O. Fanger in 1972. It is used to express the human body's feelings of cold and heat in the environment. Predicted Percentage of Dissatisfied (PPD) indicates how many percent of the PMV comfort indicators is uncomfortable. The factors affecting the PMV index include indoor environmental factors as well as human factors, as follows.
(1) Indoor Environmental Factors. These are dry bulb temperature, relative humidity, black ball temperature (average radiant temperature), and wind speed.

(2) Human Factors. These are the amount of clothing and the amount of activity.

1.1. IoT. The IoT refers to a huge network formed by the combination of device equipment and the Internet, including sensors and identification devices, radio frequency identification (RFID) devices, infrared sensors (IR), global positioning system (GPS), and temperature and humidity sensors; its purpose is to connect all the objects to the network so that the system can automatically and timely identify, locate, track, monitor, and own various applications. The concept of IoT originated from the speech of Peter T. Lewis in 1985 and then Bill Gates mentioned IoT in the book entitled "The Road to the Future" in 1995. Later, in 2005, the International Telecommunication Union (ITU) formally proposed the concept of IoT.

The IoT architecture can be divided into three layers according to the European Telecommunications Standards Institute (ETSI), namely, the sensing layer, the network layer, and the application layer $[10,11]$. The architecture is shown in Figure 1.

Sensing layer: the sensing layer uses various sensors to detect external messages and transmits the captured signals to the network layer through TCP/IP, RS485, RS232, USB, RFID, ZigBee, Bluetooth, and other transmission protocols, just as the five senses of people that receive different external stimuli.

Network layer: the network layer transmits the messages to the corresponding devices through wired or wireless communication, as based on the communication transmission function, just like human nerves.

Application layer: the information collected by the network layer is postprocessed, analyzed, and applied, just like the human brain center; applications, ranging from food, clothing, housing, travel, education, and music, as required by people, to environmental monitoring, traffic supervision, and resource management, as required by industrial, agricultural, medical, learning, and business operations, can be connected with IoT.

This study uses ESP8266 for the wireless transmission, which is an ultra-low-power UART-Wi-Fi transmission module designed for mobile devices and IoT applications and can connect devices to Wi-Fi networks or serve as wireless base station for Internet or LAN communication, thus realizing the networking functions. ESP8266 can be widely used in smart grids, smart traffic, smart homes, handheld devices, industrial control, etc. Its main features are as follows.

1.1.1. Support Three Wireless Network Protocol Standards. The IEEE wireless network standard is developed by the IEEE Standards Institute. ESP8266 supports three wireless network standards $802.11 \mathrm{~b} / \mathrm{g} / \mathrm{n}$, as shown in Table 1 [12].

1.1.2. The Supported Three Work Patterns Are As Follows. STA pattern: the ESP8266 module connects to the Internet via the 


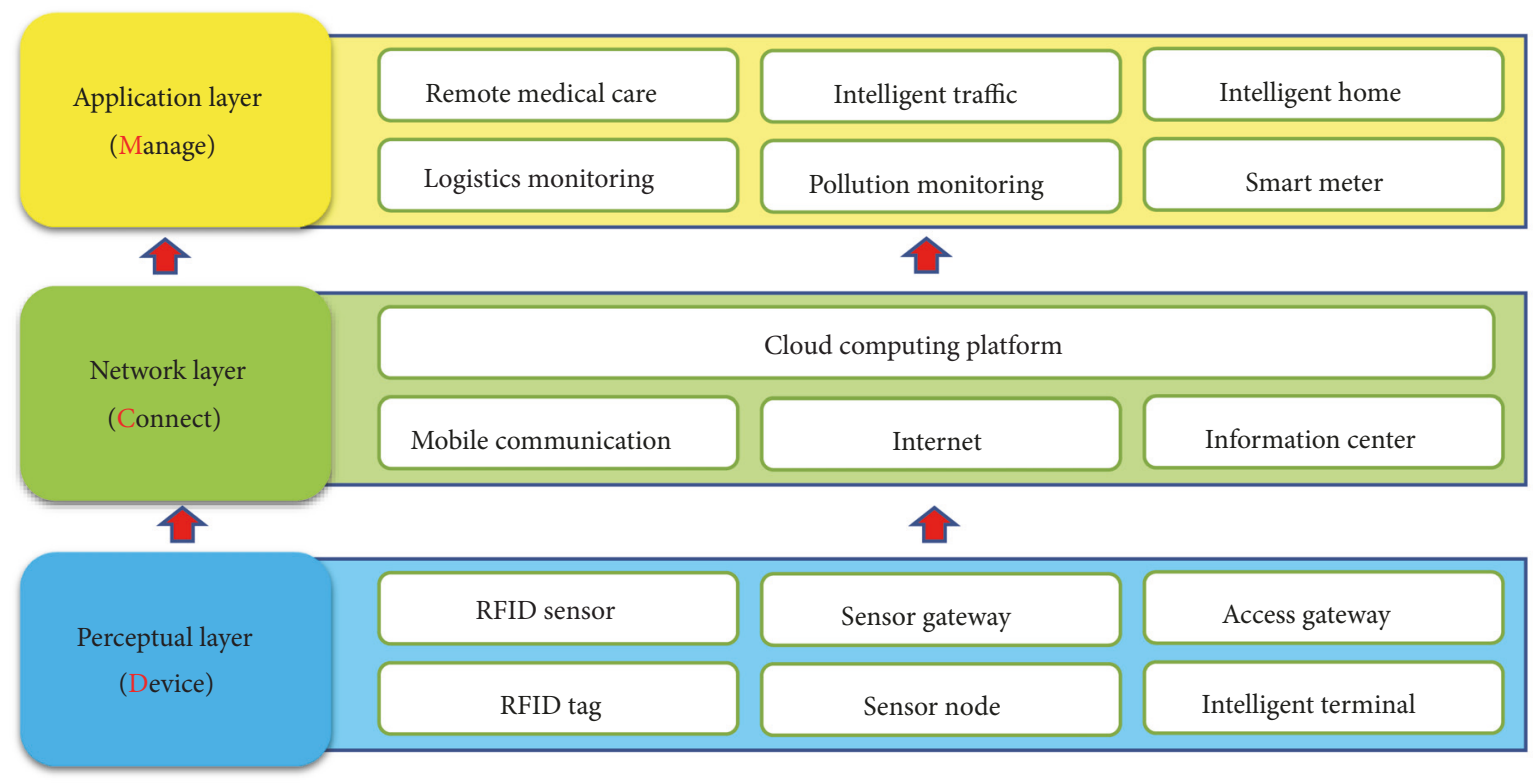

FIgURE 1: IoT architecture.

TABLe 1: IEEE802.11.

\begin{tabular}{lcccc}
\hline & & IEEE & IEEE & IEEE \\
& Protocol items & $802.11 \mathrm{~b}$ & $802.11 \mathrm{~g}$ & $802.11 \mathrm{n}$ \\
\hline Frequency & & $2.4 \mathrm{G} \mathrm{Hz}$ & $2.4 \mathrm{G} \mathrm{Hz}$ & $2.4 \mathrm{G} \mathrm{Hz}$ \\
\hline Transmission rate & Indoor & $1-11 \mathrm{Mbps}$ & $6-54 \mathrm{Mbps}$ & $7.2-72.2 \mathrm{Mbps}$ \\
\hline \multirow{2}{*}{ Range } & Outdoor & $35 \mathrm{~m}$ & $38 \mathrm{~m}$ & $70 \mathrm{~m}$ \\
& & $140 \mathrm{~m}$ & $140 \mathrm{~m}$ & $250 \mathrm{~m}$ \\
\hline
\end{tabular}

router and remotely controls the device through the Internet via a mobile phone or computer.

AP pattern: as a hot spot, the ESP8266 module communicates directly with mobile phones or computers and realizes wireless LAN control.

STA+AP pattern: the coexistence pattern of the above two patterns can be seamlessly switched through Internet control and increase operational convenience.

1.1.3. Compatibility with Multiple Development Environments. The ESP8266 program development originally required the FreeRTOS real-time operating system and was written in $\mathrm{C}$ language, but later someone developed a third-party library for the Arduino IDE, which enabled the writing of the ESP8266 control program in the Arduino IDE development environment and greatly reduced the learning threshold of program development; afterwards, more software personnel joined and proposed more development methods, such as Java and Python, which render ESP82663 more and more compatible.

Low energy consumption: ESP8266 uses a single 3.3V power supply, which has low transmission energy consumption and is suitable for battery power supply applications.

Low cost: ESP8266 is a low-cost Wi-Fi microcontroller developed by Shenzhen Lexin Information Co., Ltd., and its price is about one-tenth that of other Wi-Fi controllers.
1.2. Thermal Comfort Assessment Method. Since the beginning of the 20th century, many scholars have conducted research on assessment methods for indoor thermal comfort and put forward a series of assessment indicators, such as the temperature-humidity-wind index (THWI), standard effective temperature (SET), and predicted mean vote (PMV), which provide important basis and assessment methods for thermal environment considerations and architectural design assessments.

1.2.1. Apparent Temperature (THWI). Apparent temperature was first proposed in the A universal scale of apparent temperature, as published by Steadman (1984). As the formula is affected by temperature, humidity, and wind speed, it is also known as the Temperature-Humidity-Wind Index and often quoted by the Central Weather Bureau for predicting the apparent temperature [13]. The specific formulas are as follows:

$$
\text { THWI }=1.07 \mathrm{~T}+0.2 \mathrm{e}-0.65 \mathrm{~V}-2.7
$$

where THWI is apparent temperature, $\mathrm{V}$ is wind speed, $\mathrm{T}$ is temperature $\left({ }^{\circ} \mathrm{C}\right)$, and e is vapor pressure $(\mathrm{hPa})$;

$$
\mathrm{e}=\frac{R H}{100} \times 6.105 \times \exp \frac{17.27 T}{237.7+T}
$$


TABLE 2: Impact of SET on the human body.

\begin{tabular}{|c|c|c|c|c|}
\hline $\mathrm{SET} /{ }^{\circ} \mathrm{C}$ & Thermal feeling & Discomfort & $\begin{array}{c}\text { Human body temperature } \\
\text { regulation }\end{array}$ & Health state \\
\hline 40 & Very hot & Intolerable & $\begin{array}{c}\text { Water cannot be evaporated from } \\
\text { the skin }\end{array}$ & $\begin{array}{l}\text { Risk of heat } \\
\text { stroke }\end{array}$ \\
\hline $35 \sim 40$ & Hot & Very uncomfortable & & \\
\hline 35 & & Uncomfortable & & \\
\hline $30 \sim 35$ & Warm & $\begin{array}{c}\text { Slightly } \\
\text { uncomfortable }\end{array}$ & $\begin{array}{l}\text { Sweating increases and blood } \\
\text { vessels expand }\end{array}$ & \\
\hline \multicolumn{5}{|l|}{30} \\
\hline $25 \sim 30$ & Slightly warm & & & \\
\hline 25 & & & No obvious sweating & \\
\hline $20 \sim 25$ & Neutral & Comfortable & & $\begin{array}{c}\text { Normal } \\
\text { health state }\end{array}$ \\
\hline 20 & Slightly cool & & Blood vessels retract & \\
\hline $15 \sim 20$ & Slightly cold & $\begin{array}{c}\text { Slightly } \\
\text { uncomfortable }\end{array}$ & & \\
\hline 15 & & & Change behaviors & Body \\
\hline $10 \sim 15$ & Cold & & Start chilling & metabolism is \\
\hline 10 & Very cold & Uncomfortable & & weakened \\
\hline
\end{tabular}

where $\mathrm{RH}$ is relative humidity $(\%), \mathrm{T}$ is temperature $\left({ }^{\circ} \mathrm{C}\right)$, and e is vapor pressure $(\mathrm{hPa})$.

1.2.2. Standard Effective Temperature (SET). The Standard Effective Temperature is a formula derived from the twonode human body temperature regulation model, as proposed by Gagge in 1971 [14]. Table 2 shows the effect of standard effective temperature on the human body. The model considers the human body as two layers, namely, the core layer and the skin layer. While the metabolism produces heat in the core layer, some of it is directly lost to the environment through breathing, some of the heat is transferred to the surface of the skin and partially lost by the evaporation of sweat, and the remaining heat is transferred to the surface of clothes and then lost to the environment through radiation and convection.

The standard effective temperature (SET) is defined as follows: when a person wearing standard clothes (thermal resistance $0.6 \mathrm{clo}$ ) is in an environment where the relative humidity is $50 \%$, the air is approximately stationary (wind speed $0.1 \mathrm{~m} / \mathrm{s}$ ), and the air temperature is the same as the average radiant temperature; if the average skin temperature and skin moisture are the same as those of the actual environment and actual Clothing resistance, the human body will have the same heat dissipation in the standard environment and the actual environment. At this time, the air temperature of the standard environment is the standard effective temperature (SET) of the actual environment. The specific formula is as follows:

$$
\begin{aligned}
M_{c r} c_{c r} \frac{d T_{c r}}{d t}= & \mathrm{M}+M_{s h}-W-Q_{r e} \\
& -\left(\mathrm{K}+m_{b l} c_{p, b l}\right)\left(T_{c l}-T_{s k}\right)
\end{aligned}
$$

$$
M_{s k} c_{s k} \frac{d T_{s k}}{d t}=\left(K+m_{b l} c_{p, b l}\right)\left(T_{c l}-T_{s k}\right)-Q_{d r}-Q_{e v}
$$

where $M_{c r}$ and $M_{s k}$ are the core layer mass and skin layer mass per unit surface area; $c_{c r}$ and $c_{s k}$ are the average specific heat capacity of the core layer and the skin layer; $T_{c r}$ and $T_{s k}$ are the temperature of core layer and skin layer; $t$ is time; $\mathrm{M}$ is the metabolic rate per unit surface area; $M_{s h}$ is the heat generated by chilling regulation per unit surface area; $\mathrm{W}$ is the mechanical work per unit surface area; $Q_{r e}$ is the respiratory heat loss per unit surface area; $Q_{d r}$ is the apparent heat exchange between the unit surface area and the environment; $Q_{e v}$ is the latent heat exchange between the unit surface area and the environment; $\mathrm{K}$ is the thermal conductivity coefficient between the core layer and the skin layer; $m_{b l}$ is the blood flow between the core layer and the skin layer; $c_{p, b l}$ is the specific heat capacity of the blood.

1.2.3. Predicted Mean Vote. The Predicted Mean Vote (PMV) was proposed for the human body heat balance model, as published by Fanger (1972). This model is used to express the human body feelings of cold and heat in the environment; based on the experiment over 1,300 subjects, the PMV equation was derived by referring to various factors affecting thermal comfort, the average number of votes for the hot and cold feelings in the environment was calculated, and the Predicted Percentage of Dissatisfied (PPD) was obtained. The PMV and PPD indicators are used as the final assessment method, as listed in the ISO7730 international standard in 1984, which considers the most comprehensive influencing factors of human thermal comfort and is also the most common indoor thermal comfort assessment indicator [1517].

1.2.4. Predicted Mean Vote (PMV). Fanger analyzed the heat balance of the human body, as summarized into (5) to (8) 
TABLE 3: Levels of thermal comfort.

\begin{tabular}{lccccccc}
\hline PMV & +3 & +2 & +1 & 0 & -1 & -2 & -3 \\
\hline Thermal feeling & Hot & Warm & Slightly warm & Moderate & Slightly cool & Cool & Cold \\
\hline
\end{tabular}

through the heat exchange between the human body and the environment; there are six main parameters affecting thermal comfort in the formulas: Ambient temperature $\left(t_{a}\right)$, mean radiant temperature $\left(t_{r}\right)$, relative humidity $(\mathrm{RH})$, indoor wind speed $\left(V_{a r}\right)$, Clothing resistance $\left(I_{c l}\right)$, and metabolic rate $(\mathrm{M})$ :

$$
\begin{aligned}
& \mathrm{PMV}=\left(0.303 \times e^{-0.036 M+0.028}\right) \times\left\{(\mathrm{M}-\mathrm{W})-3.05 \times 10^{-3}\right. \\
& \times\left[5733-6.99 \times(\mathrm{M}-\mathrm{W})-P_{a}\right]-0.42 \times[(\mathrm{M}-\mathrm{W})-58.15] \\
& -1.7 \times 10^{-5} \times \mathrm{M} \times\left(5867-P_{a}\right)-0.0014 \times \mathrm{M} \times\left(34-t_{a}\right) \\
& -3.96 \times 10^{-8} \times f_{c l} \times\left[\left(t_{c l}+273\right)^{4}-\left(t_{r}+273\right)^{4}\right]-f_{c l} \times h_{c} \\
& \left.\times\left(t_{c l}-t_{a}\right)\right\} \\
& t_{c l}=35.7-0.028(M-W)-I_{c l}\left\{3.96 \times 10^{-8}\right. \\
& \left.\times f_{c l}\left[\left(t_{c l}+273\right)^{4}-\left(t_{r}+273\right)^{4}\right]+f_{c l} \times h_{c} \times\left(t_{c l}-t_{a}\right)\right\} \\
& f_{c l}= \begin{cases}1.00+1.290 I_{c l}, & \text { for } I_{c l} \leq 0.078 m^{2} K / W \\
1.05+0.645 I_{c l}, & \text { for } I_{c l}>0.078 m^{2} \mathrm{~K} / W\end{cases} \\
& h_{c} \begin{cases}2.38 \times\left|t_{c l}-t_{a}\right|^{0.25}, & \text { for } 2.38 \times\left|t_{c l}-t_{a}\right|^{0.25}>12.1 \times \sqrt{V_{a r}} \\
12.1 \times \sqrt{V_{a r}}, & \text { for } 2.38 \times\left|t_{c l}-t_{a}\right|^{0.25}<12.1 \times \sqrt{V_{a r}}\end{cases}
\end{aligned}
$$

where $\mathrm{W}$ is the effective external work of the human body; $P_{a}$ is the vapor partial pressure of water; $f_{c l}$ is the surface area coefficient of clothing; $t_{c l}$ is the surface temperature of clothing; $h_{c}$ is the convective heat dissipation coefficient. The calculated PMV is generally in compliance with the ASHRAE 7-point system, 0 being moderate, +3 being hot, and -3 being cold. The specific levels are shown in Table 3.

Mean radiant temperature (MRT) was mainly used to measure indoor temperature in the early days, but it has actually been used in outdoor environmental measurements. The definition of MRT refers to the heat radiation effect of the surface around the environment on the human body and is also one of the important meteorological parameters of heat balance of the human body, which can reflect the diffuse sunlight, the insolation, the short-wave reflection, the atmospheric reflection, and the long-wave radiation on the surface of the surrounding environment. It is also associated with outdoor shading, wall hue, and planting greening. Moreover, when the ambient temperature and the air temperature are too far apart, the human body warm feeling must consider the combined effect of the air temperature and the surrounding radiation. The general tool used to determine the average radiant temperature is a metal black ball thermometer that measures the combined effects of three climatic factors: ambient temperature, airflow, and radiation in the surrounding environment and calculates it in

$$
\mathrm{MRT}=\mathrm{T}_{\mathrm{g}}+0.237 \times \sqrt{\mathrm{V}} \times\left(\mathrm{T}_{\mathrm{g}}-\mathrm{T}_{\mathrm{a}}\right)
$$

Here, MRT means that the average radiation temperature unit is ${ }^{\circ} \mathrm{C}, \mathrm{V}$ means that the wind speed unit is $\mathrm{m} / \mathrm{s}, \mathrm{T}_{\mathrm{g}}$ means that the black sphere temperature unit is ${ }^{\circ} \mathrm{C}$, and Ta means that the dry bulb temperature unit is ${ }^{\circ} \mathrm{C}$.

1.2.5. $P P D$. $P P D$ is the predicted percentage of the number of people who feel uncomfortable in the total number of people in a given thermal environment according to the predicted mean vote. According to people's environmental sense, the number of votes is calculated as the PPD, which is a function of PMV and reflects the percentage of people who are dissatisfied, as shown in (10). People's thermal feelings of the environment are different. Even when PMV $=0$ under comfortable conditions, the curve in Figure 2 reflects that 5\% of people are not satisfied:

$$
\mathrm{PPD}=100-95 e^{-\left(0.03353 \times P M V^{4}+0.2179 \times P M V^{2}\right)}
$$

Since it is not possible or necessary to make $100 \%$ people comfortable or satisfied, PPD has significance. Even if $\mathrm{PMV}=0$, there are still some people that will be dissatisfied in a moderate environment; therefore, ISO and ASHRAE define $-0.5<\mathrm{PMV}<0.5$ according to the PMV-PPD pointer, and the corresponding PPD is $<10 \%$, which is used as a thermal comfort standard for indoor environments.

1.3. Related Parameter Standards of Thermal Comfort. The sources of relevant parameters used in this study are mainly ISO international standard indicators, as well as related standards and influences from related papers.

1.3.1. International Standard Indicators. The parameters referred to in this study are mainly derived from international standard indicators, as shown in Table 4.

Initially, there are long-term research results such as Kansas State University, the American Society of Heating, Refrigerating, and Air-Conditioning Engineers' ASHRAE 5574 standard, namely, the thermal comfort conditions of people living, and the later ASHRAE 55.81 standard, ASHRAE 55.1992 standard, and ASHRAE 55.2004 standard. In 1996, there was the use of 7-level thermal sensory indicators: cold, cool, cool, neutral, slightly warm, warm, and hot.

For the general case, we can directly test the indoor dry bulb temperature, relative humidity, wind speed, and other thermal environment parameters by using the thermal comfort test system and then combine the questionnaire and ASHRAE 7-level thermal comfort indicators to investigate and record the residents' thermal sensation. It is also possible to derive the distribution of the thermal environment. Due to individual differences in people, a $100 \%$ thermal environment that satisfies everyone's comfort requirements is impossible. Therefore, any indoor climate must meet the comfort requirements of most people as much as possible. Human subjective adaptability can be considered as a major cause of differences 


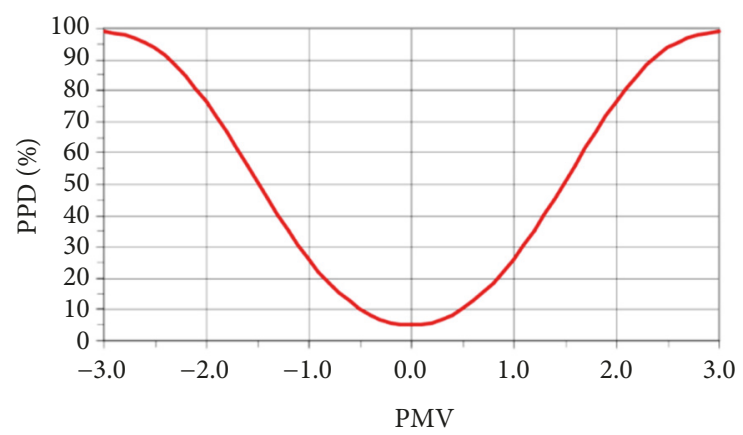

FIGURE 2: Relationship between PMV and PPD.

TABLE 4: International standard indicators.

\begin{tabular}{lc}
\hline Standard & Content \\
\hline ISO 7730 & Thermal comfort indicator \\
\hline ISO 7726 & Environmental parameters and measurement methods \\
\hline ISO 8996 & Metabolic rate \\
\hline ISO 9920 & Clothing resistance \\
\hline ISO 13731 & Term definition \\
\hline ISO 14415 & Thermal comfort indicator for special identity \\
\hline ASHRAE 55 & Thermal comfort indicator \\
\hline
\end{tabular}

in the results of laboratory and field tests, including physical, behavioral, and primarily psychological adaptation. The literature has pointed out that the judgment of thermal sensation depends to a large extent on the background of the people and an expectation of the environment. Therefore, comfort research should have both laboratory experiments and field test analysis. They believe that differences in architectural forms, climate, ethnicity, etc. may cause people around the world to feel differently in the same thermal environment and have different requirements for thermal comfort.

Thermal comfort is the state of the human body's perception and preference for physical environments such as temperature, humidity, and wind speed. It can be confirmed by subjective assessment (ASHRAE 55). If the environment is not good, it will affect the work efficiency of the human body, and even it is more likely to cause health hazards.

1.3.2. Clothing Resistance. Clothing Resistance (Clo) in this study is based on ISO9920 and is referred to as Table 5 [18].

1.3.3. Metabolic Rate. Metabolic rate in this study is based on ISO8996, and the main activities of indoor individuals are the main research target. The standard unit of calculation is Metabolic Equivalent (Met), which in this study is converted into the heat produced per unit surface area of the human body (W), as shown in Table 6 [19].

1.3.4. Impact of Wind Speed on Human Body and Work. This study refers to the research results of wind speed impact in related journals, in order to set the indoor optimal wind speed range, and wind speed affects the human body and work efficiency, as shown in Table 7 [20].
1.3.5. Optimal Relative Humidity. The relative humidity range of this study is based on the research data published by AV Arundel and other scholars in the Environmental Health Perspectives (EHP) in the National Environmental Health Science Institute. The proposed optimal relatively humidity range is $40 \sim 60 \%$ [21].

1.4. Fuzzy Theory. The fuzzy theory was proposed in a paper called Fuzzy Sets, as published by Zadeh (1965), and mainly included the fuzzy set theory, fuzzy logic, fuzzy reasoning, and fuzzy control $[22,23]$. Specifically, among the facets of fuzzy theory, fuzzy control was the first to receive academic attention and yield research results. The first scholar to use fuzzy theory in the field of control was Mamdani (1974), who verified fuzzy control by the steam engine model produced by his research team.

Fuzzy control includes fuzzification, fuzzy rule base, fuzzy inference, and defuzzification. The role of fuzzification is to convert the exact input quantity into fuzzy quantity; the fuzzy rule base includes a series of IF-THEN rules represented by fuzzy linguistic variables; fuzzy inference is to simulate the human decision-making process based on the fuzzy rule base; the purpose of defuzzification is to transform the fuzzy quantity obtained by fuzzy inference into the clear quantity actually used for control. This study applies fuzzy control as the control method for the experimental load.

\section{System Architecture}

This paper divides the system structure into three parts, the perception layer, the network layer, and the application layer, as shown in Figure 3. In the sensing layer, four kinds of environmental sensors are used, including an air volume 
TABLE 5: Clothing resistance.

\begin{tabular}{|c|c|c|c|c|c|}
\hline \multicolumn{2}{|c|}{ Clothing type } & \multirow{2}{*}{$\frac{\text { Resistant unit (Clo) }}{0.12}$} & \multicolumn{2}{|r|}{ Clothing type } & \multirow{2}{*}{$\frac{\text { Resistant unit (Clo) }}{0.03}$} \\
\hline \multirow{8}{*}{ Garment } & Vest & & \multirow{6}{*}{ Underwear } & Briefs & \\
\hline & Short shirt & 0.15 & & Boxers & 0.1 \\
\hline & Thin long shirt & 0.2 & & Bra & 0.03 \\
\hline & Long shirt & 0.25 & & Undershirt & 0.04 \\
\hline & Cotton long shirt & 0.3 & & Short-sleeve underwear & 0.09 \\
\hline & Thin sweater & 0.2 & & Long-sleeve underwear & 0.12 \\
\hline & Sweater & 0.28 & \multirow{2}{*}{ Pants } & Sport pants & 0.06 \\
\hline & Thick sweater & 0.35 & & Thin pants & 0.2 \\
\hline \multirow{6}{*}{ Coat } & Sleeveless shirt & 0.2 & \multirow{3}{*}{ Pants } & Pants & 0.25 \\
\hline & Thin jacket & 0.25 & & Cotton pants & 0.28 \\
\hline & Jacket & 0.35 & & Thick pants & 0.35 \\
\hline & Thick jacket & 0.4 & \multirow{3}{*}{ Others } & Short socks & 0.02 \\
\hline & Overcoat & 0.6 & & Socks & 0.05 \\
\hline & Hoodie & 0.7 & & Long socks & 0.1 \\
\hline \multirow{4}{*}{ Skirt } & Thin skirt & 0.15 & \multirow{4}{*}{ Others } & Stockings & 0.03 \\
\hline & Thick skirt & 0.25 & & Shoes (thin) & 0.02 \\
\hline & Short-sleeve skirt & 0.2 & & Shoes (thick) & 0.04 \\
\hline & Long-sleeve skirt & 0.4 & & Boots & 0.1 \\
\hline
\end{tabular}

TABLE 6: Metabolic rate.

\begin{tabular}{lll}
\hline Activity & & Metabolic rate $\left(\mathrm{M} / A_{D u}\right)$ \\
\hline Sleep & $40 \mathrm{~W} / \mathrm{m}^{2}$ & $0.69 \mathrm{Met}$ \\
\hline Sit resting & $55 \mathrm{~W} / \mathrm{m}^{2}$ & $0.95 \mathrm{Met}$ \\
\hline Stand resting & $70 \mathrm{~W} / \mathrm{m}^{2}$ & $1.2 \mathrm{Met}$ \\
\hline Sit working & $70 \mathrm{~W} / \mathrm{m}^{2}$ & $1.2 \mathrm{Met}$ \\
\hline Walk $(2 \mathrm{Km} / \mathrm{h})$ & $110 \mathrm{~W} / \mathrm{m}^{2}$ & $1.9 \mathrm{Met}$ \\
\hline
\end{tabular}

TABLE 7: Impact of wind speed on the human body and work.

\begin{tabular}{lc}
\hline Wind speed & Impact on the human body and work \\
\hline $0 \sim 0.3 \mathrm{~m} / \mathrm{s}$ & Not easy to perceive \\
\hline $0.3 \sim 0.5 \mathrm{~m} / \mathrm{s}$ & Joyful and does not affect work \\
\hline $0.5 \sim 1.0 \mathrm{~m} / \mathrm{s}$ & Joyful but beware of thin paper being blown away (such as manuscript paper) \\
\hline $1.0 \sim 1.5 \mathrm{~m} / \mathrm{s}$ & Slight wind impact and annoying blowing \\
\hline $1.5 \sim 7.0 \mathrm{~m} / \mathrm{s}$ & Obvious wind impact, blowing away thin paper, and scattering the thick paper \\
& $\begin{array}{c}\text { Maintain good work efficiency } \\
\text { Revise to appropriate wind speed }\end{array}$ \\
\hline
\end{tabular}

sensor, a fine aerosol sensor, a carbon dioxide sensor, and a temperature and humidity sensor, as shown in Figures 4 and 5. The position of the sensor is set as shown in Figure 6 [24], in which node 1 and node 3 are additionally equipped with an infrared emission module to control the air conditioner, dehumidifier, and air cleaner. In the network layer, the microcontroller communicates with the entire system through the communication method of ESP8266 wireless $\mathrm{Wi}-\mathrm{Fi}$ transmission. In the application layer, the system performs corresponding processing according to the signals received in the sensing layer. The system first displays the monitoring information on the computer interface, and the system uses the method mentioned in this paper for analysis and processing. When the system finds that the indoor environmental data does not match the set value, the system will use the wireless control method to control the indoor load equipment to achieve the desired result of thermal comfort. The impact of the system control load on the indoor environment is again processed by the sensing layer. The network layer of the system transmits the signal to the application layer. The application layer of the system stores and processes the data, and the system outputs the results of the analysis to improve the load control, ultimately achieving better thermal comfort environment control $[25,26]$. 


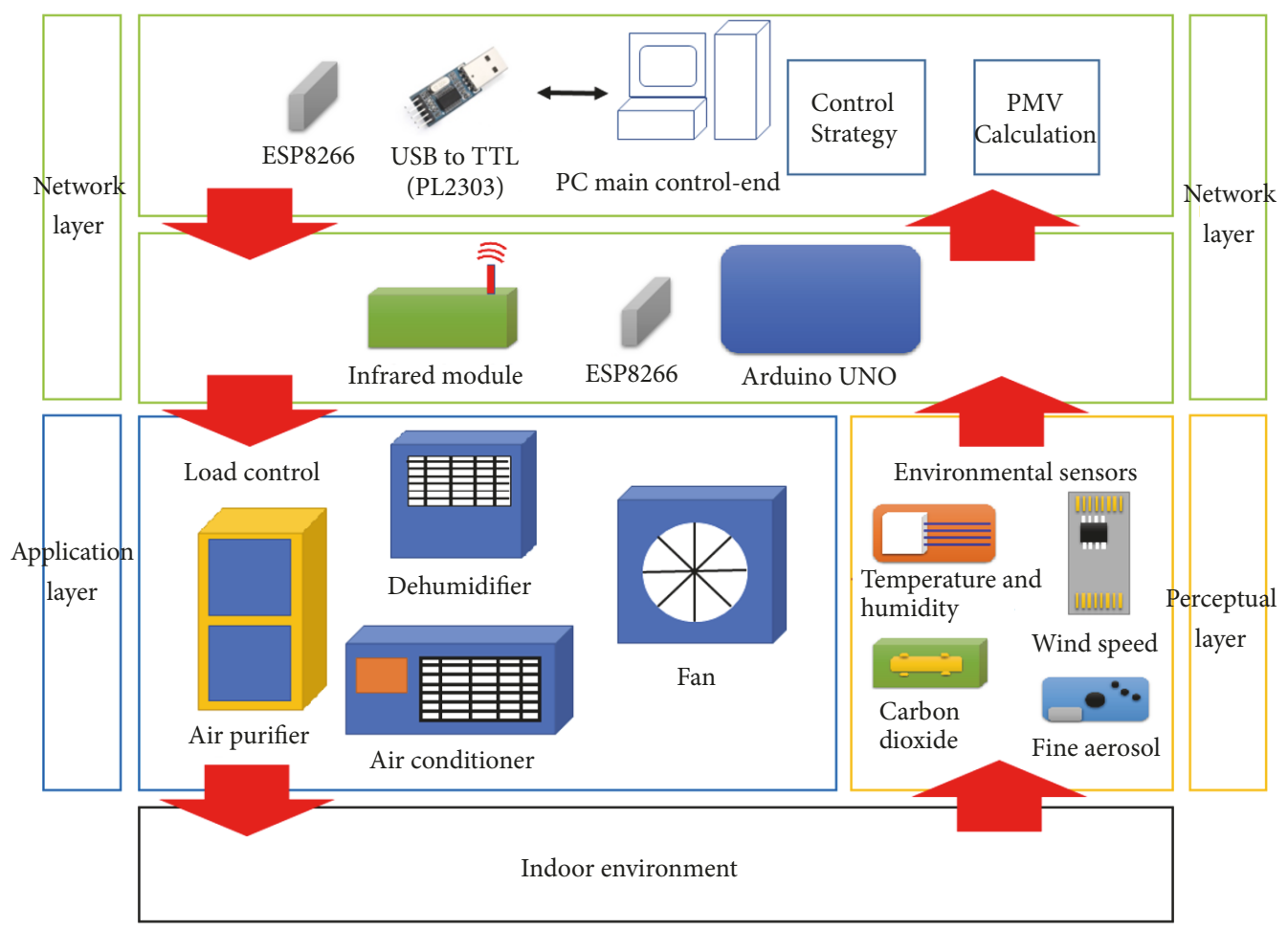

Figure 3: System architecture.

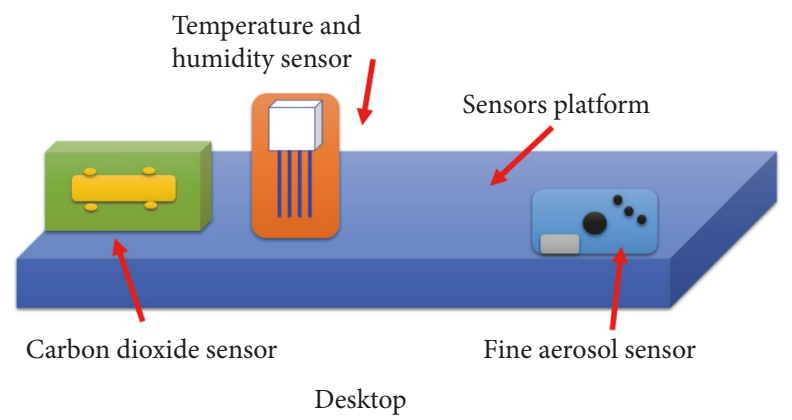

FIGURE 4: Environmental sensing nodes (front view).

Our team placed multiple sensor devices directly on the indoor table or in the obvious, consistent with people's perspectives. The time when the sensor is deployed is the normal working hours of people, starting from 9:00 in the morning to about 3:00 in the afternoon.

All sensor devices are connected to the Arduino microcontroller. The Arduino hardware module collects the measured data of the sensor and transmits it to the PC control center through the communication module of the ESP8266. The ESP8266 uses Wi-Fi communication protocols to transfer data. After the PC control center performs actual environmental data analysis, the PC control center will send infrared control signals to adjust the load of various types of electrical equipment. The adjustment control signals of these electrical devices are transmitted using wireless infrared rays. When the PC control center finds that the sensing data of the actual environment is different from the data set by the precontext, the PC control center will send a correction signal to the electrical device. Therefore, the proposed system defines the sensor device as the sensing layer of the system. The PC Control Center is responsible for cloud data operations, which the system defines as the network layer. The environmental electrical equipment is regulated by the control signal, so these load devices will be defined by the system as the application layer. When the sensing layer transmits environmental data to the network layer, this network layer is the control center of the system. The control center compares the actual data with preset values. When the difference between the actual value and the set value exceeds the threshold, the control center transmits a control signal to the load terminal for correction control. This load side is the electrical equipment of our system, that is, the application layer. This threshold is based on our different types of sensors. For example, when the temperature exceeds 


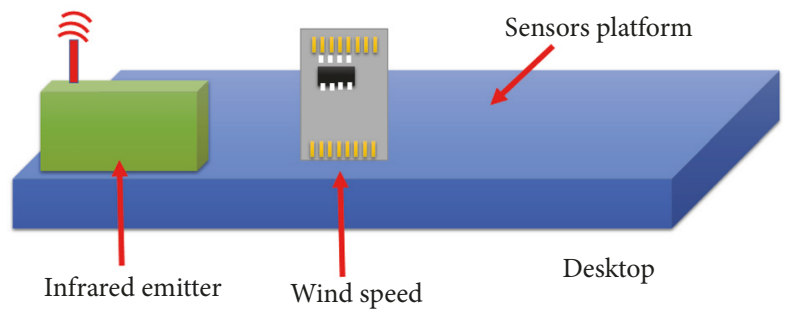

Figure 5: Environmental sensing nodes (back view).

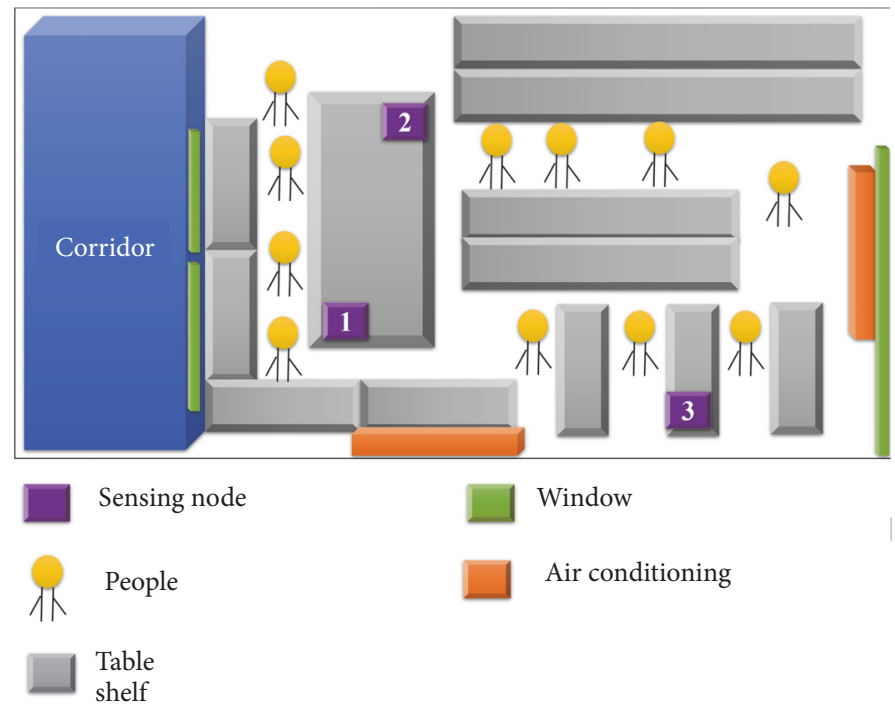

FIGURE 6: Indoor environment and positions of sensing nodes.

$2^{\circ} \mathrm{C}$, the system will automatically start the air conditioning equipment.

The $\mathrm{C}++$ programming language is used between the sensor and the Arduino microcontroller as the interface for processing data. The Arduino microcontroller transmits the sensing data to the PC Control Center via the ESP8266 chip, which is the work of transmitting the sensing data using the Wi-Fi protocol. We use JavaScript and HTML5 web pages to collect sensory data into the database and then use Visual C\#'s human interface program to perform various algorithm analyses. The ESP8266 chip that we use receives the sensing signal and the transmission control signal through the RS-232 standard interface TX, RX to complete the data signal transmission. When the control center is to perform regulation on the electrical equipment side, the system will send an infrared control signal for load correction. When the device is regulated to the range of the set value, the control center will stop the regulation action. Figure 7 shows the transmission architecture of the sensing data and control signals in this paper.

\section{Experimental Results and Analysis}

3.1. Thermal Comfort Assessment and MATLAB Simulation Analysis. In order to improve indoor thermal comfort, this study first assesses several common thermal comfort assessment methods and selects the suitable thermal comfort assessment method according to the considerations of temperature, wind speed, and humidity. The three common thermal comfort assessment methods in Section 2 are compared, and finally the predicted mean vote (PMV) is adopted as the thermal comfort standard in this study. This assessment indicator was listed in the ISO7730 international standard in 1984, considers the most comprehensive influential factors of human thermal comfort, and is also the most common indoor thermal comfort assessment indicator.

The proposed system uses MATLAB to simulate experiments of indoor environmental changes. The temperature is based on $25^{\circ} \mathrm{C}$ and the temperature range is $22^{\circ} \mathrm{C}$ to $28^{\circ} \mathrm{C}$. The humidity is based on $50 \%$ and the humidity range is $30 \%$ to $70 \%$. The wind speed ranges from 0 to $0.5 \mathrm{~m} / \mathrm{s}$. There are six main reference parameters for PMV: Ambient temperature, average radiant temperature, relative humidity, indoor wind speed, Clothing resistance, and metabolic rate. In order to effectively control the load and improve energy efficiency, the impacts of the controllable parameters of the indoor load on PMV are simulated on MATLAB, including ambient temperature, relative humidity, and indoor wind speed, which serves as the main basis for subsequent control experiments. Then, MATLAB is used to simulate the impact analysis results of ambient temperature, relative humidity, and indoor wind speed on PMV, as shown in Figures 8-10.

According to analysis of the simulation results, ambient temperature has the greatest impact on PMV, which is 


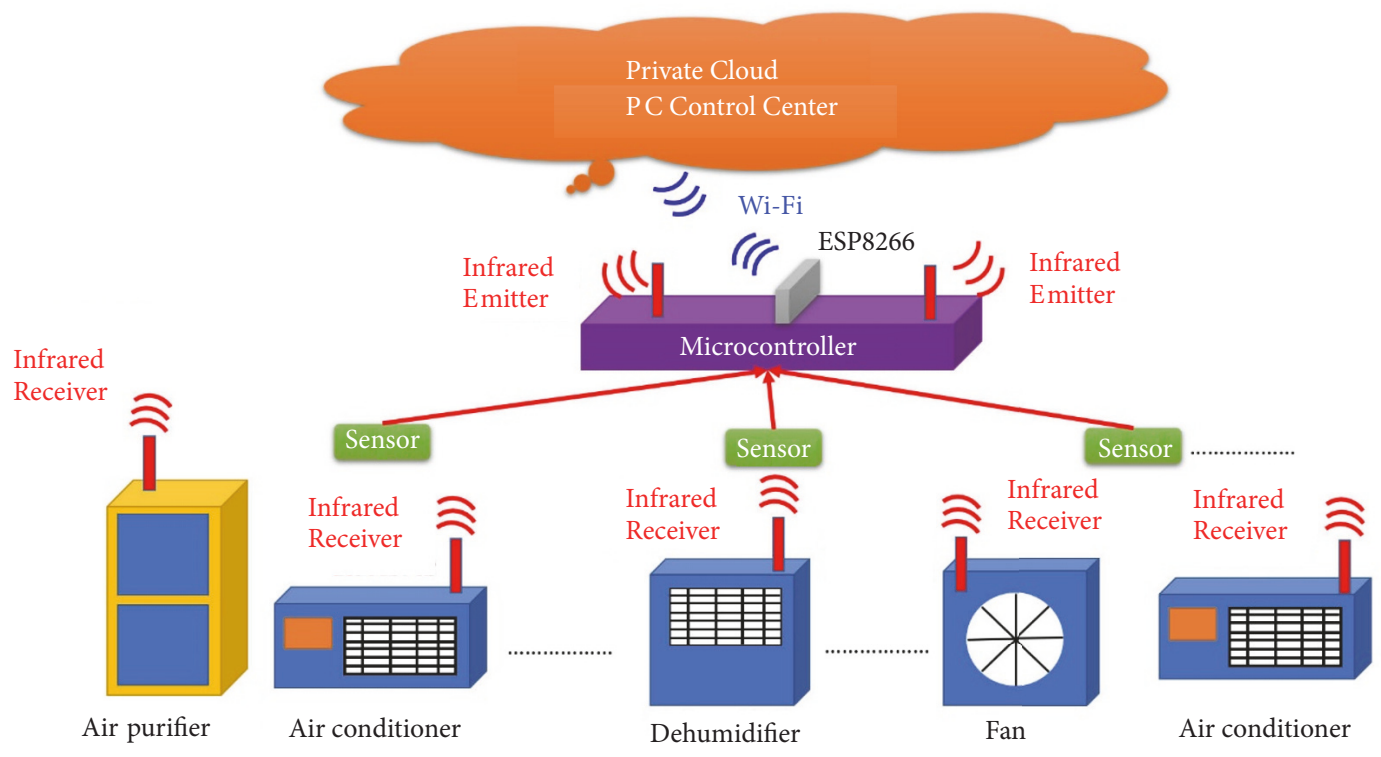

FIGURE 7: Transmission architecture diagram of sensing data and control signals.

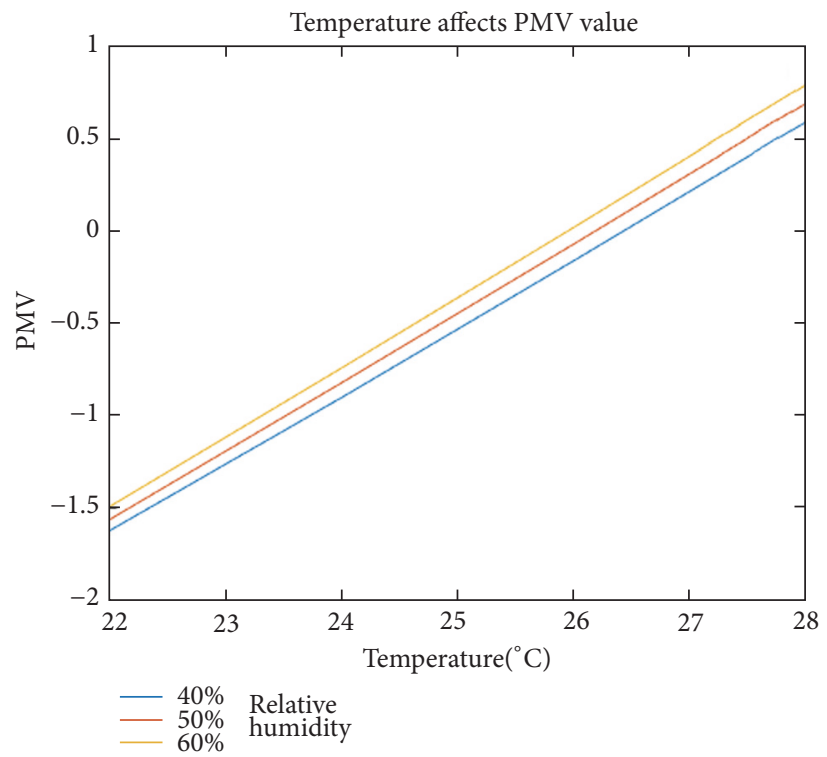

Figure 8: Impact of temperature on PMV.

presented as a linear relationship. Regarding the indoor wind speed, in the indoor static state (wind speed lower than $0.1 \mathrm{~m} / \mathrm{s}$ ), the indoor wind speed has little impact on PMV. When the indoor wind speed is greater than $0.1 \mathrm{~m} / \mathrm{s}$, the indoor wind speed increases and PMV decreases. However, as the temperature increases, the wind speed has lower impact on PMV. When the temperature decreases, the wind speed has higher impact on PMV. This trend is caused by the "wind chill effect." As the relative humidity increases, PMV increases; on the contrary, as the relative humidity decreases, PMV decreases; the impact of relatively humidity on PMV is low.

3.2. Fuzzy Control. The Multi-input Multi-output (MIMO) mathematical model is formed by the interaction between input parameters and output load when PMV is adopted as the load control standard. It is difficult for traditional PID Control to precisely control indoor thermal comfort; therefore, this study uses the fuzzy theory to control the indoor load equipment and maintain PMV within the optimal comfort range, as specified by IOS7730: $-0.5<\mathrm{PMV}<$ $0.5, \mathrm{PPD}<10 \%$. The fuzzy system architecture is shown in Figure 11, and the fuzzy control process is shown in Figure 12.

The input attribution function of the fuzzy system is set according to the MATLAB simulation results in reference to related literature data, as shown in Figure 13. The output attribution function is set according to the controllable load output, as shown in Figure 14.

After the attribution functions are obtained, as based on the MATLAB simulation results and literature data, the 


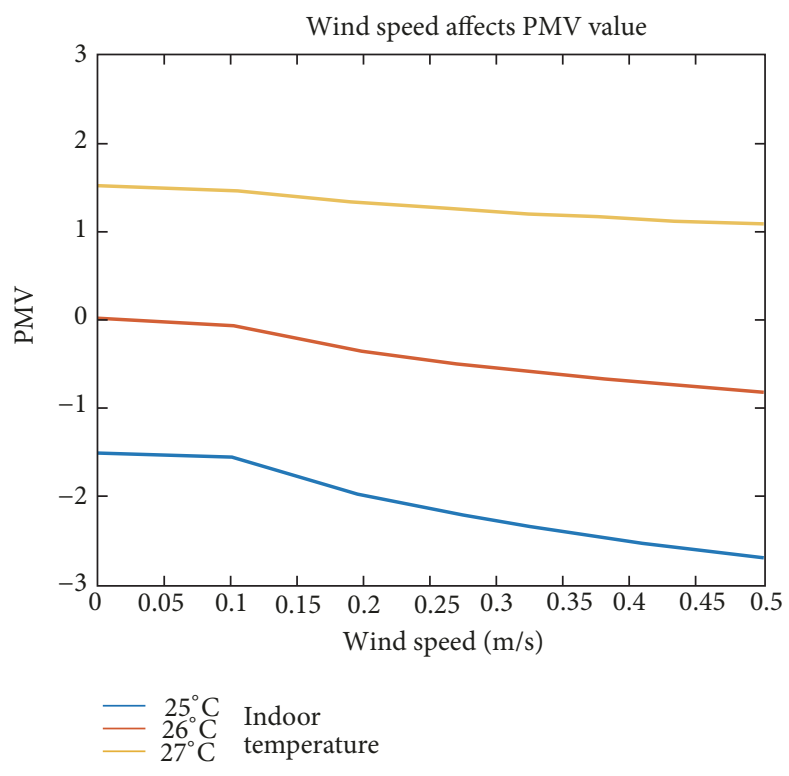

FIGURE 9: Impact of wind speed on PMV.

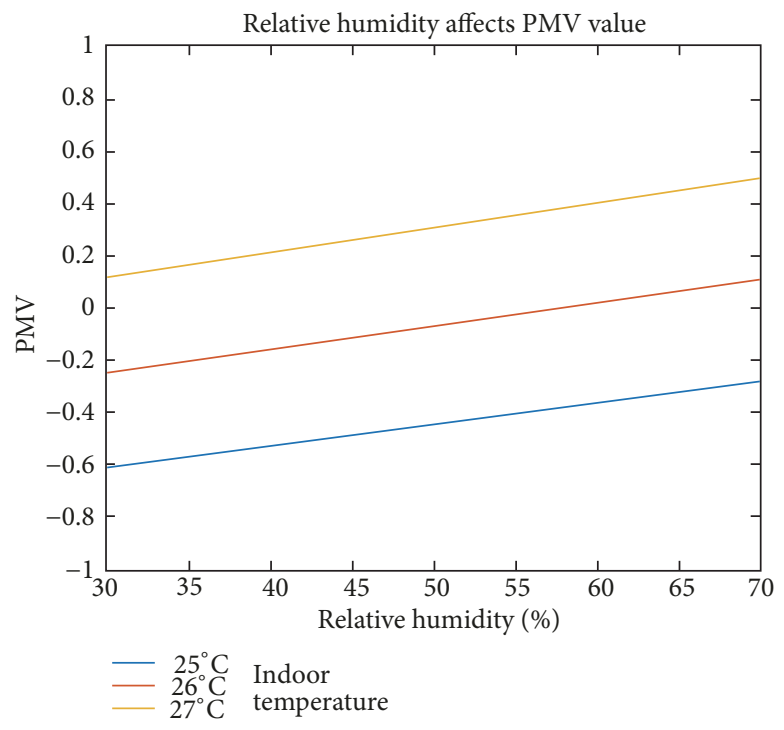

FIGURE 10: Impact of relative humidity on PMV.

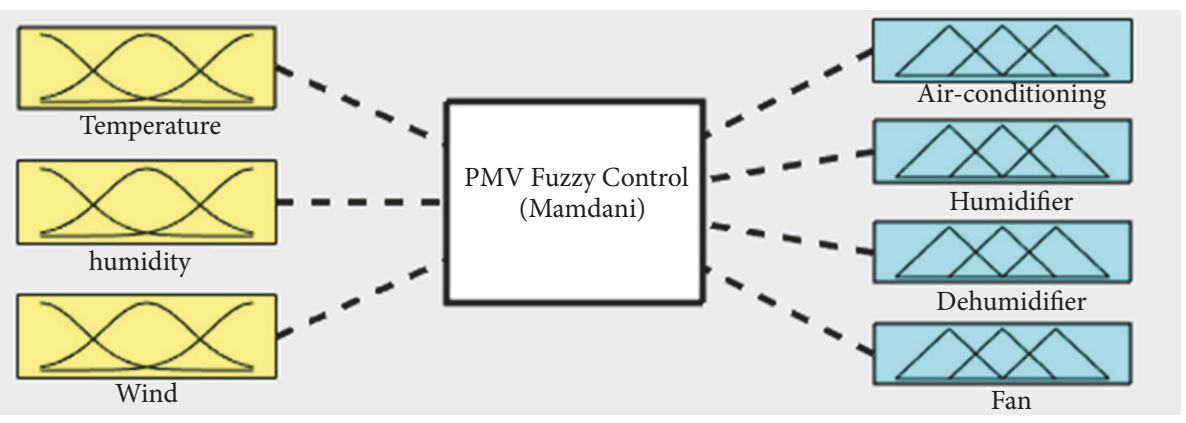

FIgURE 11: Fuzzy system architecture. 


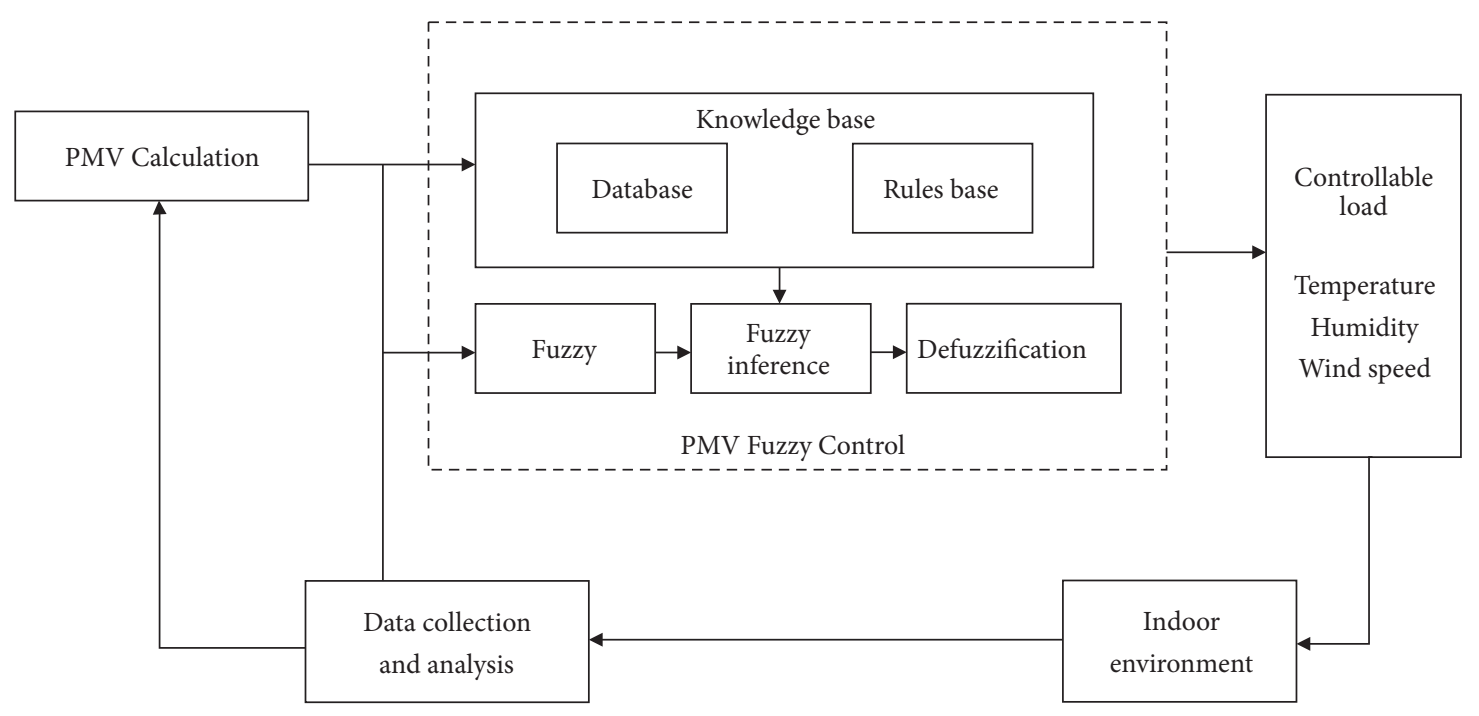

FIGURE 12: Fuzzy control process.

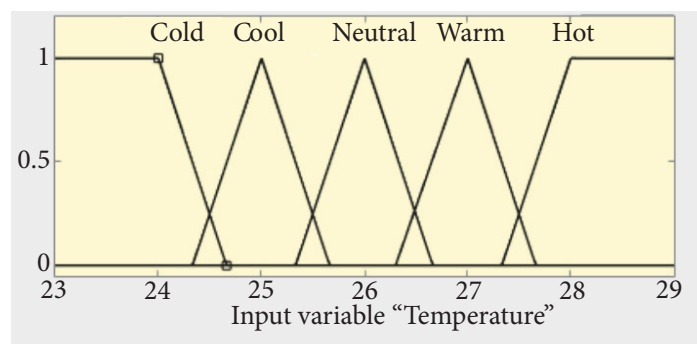

(a) Attribution function of ambient temperature

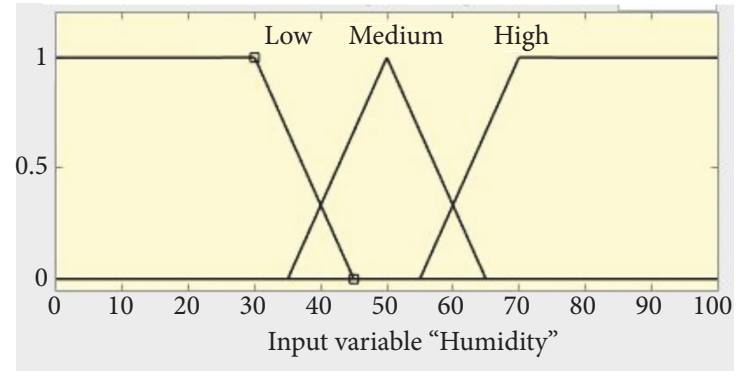

(b) Attribution function of relative humidity

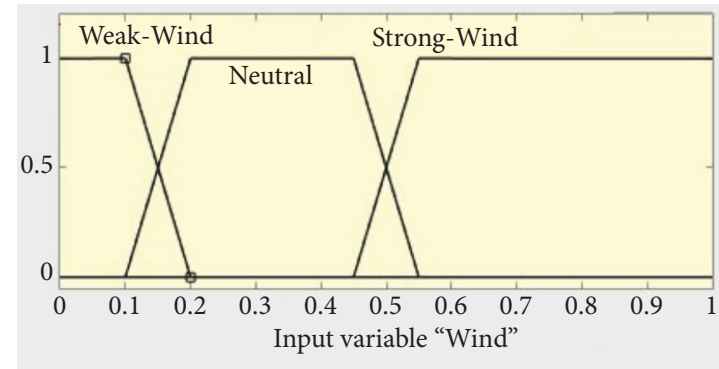

(c) Attribution function of indoor wind speed

FIgURE 13: Fuzzy system input variable description.

fuzzy logic rule base is established with the PMV range of ISO7730: $-0.5<\mathrm{PMV}<0.5, \mathrm{PPD}<10 \%$, in order that fuzzy inference can output the optimal control strategy for different environmental conditions according to the rule base. The rule base is shown in Figure 15, and the fuzzy inference is shown in Figure 16.

After the optimal comfort control method is established, in order to meet the different needs of users and the concepts of environmental protection and energy conservation, this study proposes three control modes: comfort, general, and energy-saving modes. The fuzzy logic rule libraries of the three modes are compared, as shown in Table 8.
3.2.1. Comfort Mode: $P M V=0$. $P M V$ is based on the ISO7730 standard: $-0.5<\mathrm{PMV}<0.5, \mathrm{PPD}<10 \%$, and the optimal wind speed and humidity range are set according to the standards in literature.

3.2.2. General Mode: $P M V=0.5$. The general mode is based on relaxation of the ISO standard, where the PMV is approaching 0.5 and the optimal wind speed and humidity range are set according to the standards in literature.

3.2.3. Energy-Saving Mode: $P M V=0.7$. There is no limit to the optimal wind speed or humidity, and the minimum PMV that 


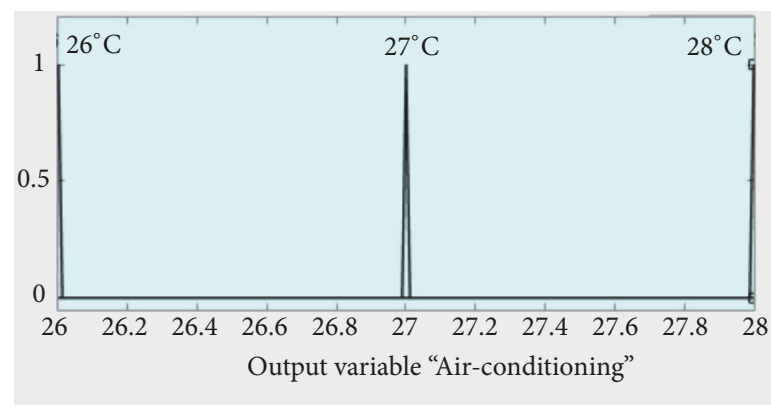

(a) Attribution function of air conditioner

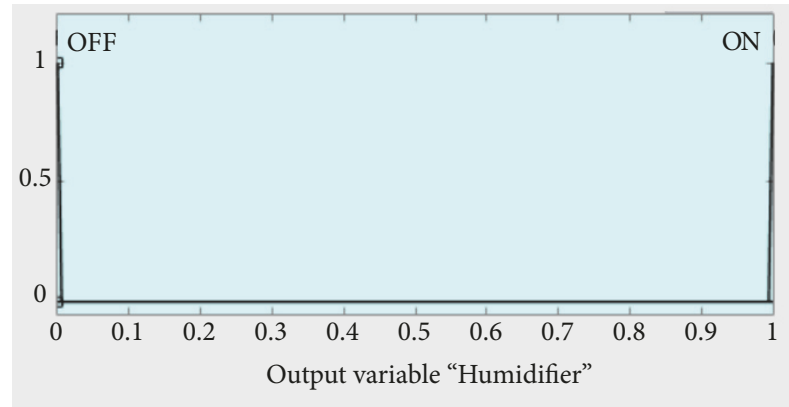

(c) Attribution function of humidifier

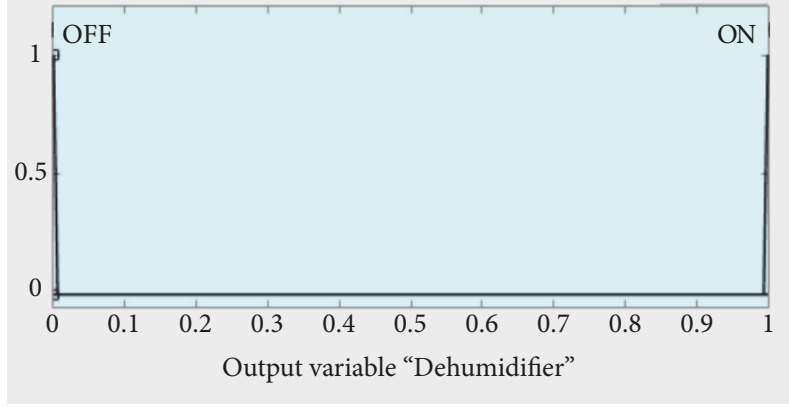

(b) Attribution function of dehumidifier

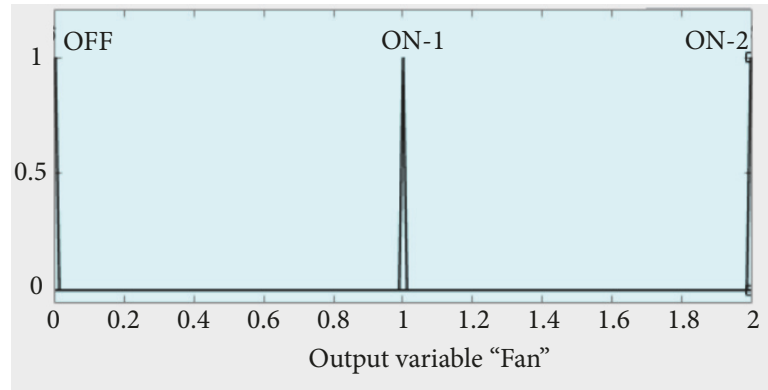

(d) Attribution function of fan

FIGURE 14: Fuzzy system output variable description.

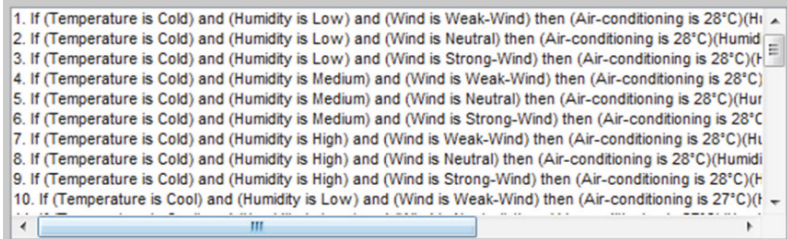

FIGURE 15: Setting of rule base.

foreign scholars believe can maintain comfort is set: $-1.0<$ $\mathrm{PMV}<1.0, \mathrm{PPD}<26 \%[4]$.

\subsection{System Implementation and Application}

3.3.1. System Monitoring Interface. Figure 17 shows the main system monitoring interface. It can be seen that the data of the three environmental monitoring nodes is monitored. At the same time, the system will store the received data in the Microsoft Excel 2013 database for subsequent experimental reference and analysis.

The monitoring data of ambient temperature, relative humidity, and indoor wind speed are combined with Fuzzy for smart thermal comfort control; if the content of fine aerosol is higher than $35 \mathrm{ug} / \mathrm{m}^{3}$, the air cleaner will be automatically turned on; if the content carbon dioxide is higher than 1000ppm, the system will beep and display a warning window.

The "Control Mode Setting" page includes many control pages. On this page, the comfort, general, and energy-saving control modes, as proposed in this study, can be selected.
3.4. Comparison of Three Control Modes. This section compares the three control modes proposed in this study and sets the indoor environmental wireless sensing nodes and wireless control load in a scattered layout, where ambient temperature (and average radiant temperature), relative humidity, and wind speed are actually measured, while clothing resistance and metabolic rate are the defaults as $0.6 \mathrm{clc}$ (average summer clothing resistance) and $1.2 \mathrm{met}$ (sit working), respectively. Specific experiments are conducted to verify the control effects of comfort, general, and energy-saving control modes; in the comfort mode, the average environmental data is as follows: Ambient temperature $26.3^{\circ} \mathrm{C}$, relative humidity $58.7 \%$, indoor wind speed $0.48 \mathrm{~m} / \mathrm{s}$, PMV 0.22, and PPD $6 \%$. In the general mode, the average environmental data is as follows: Ambient temperature $27.1^{\circ} \mathrm{C}$, relative humidity $60.5 \%$, indoor wind speed $0.49 \mathrm{~m} / \mathrm{s}, \mathrm{PMV} 0.51$, and PPD $10.4 \%$, which is estimated to save $6 \%$ more energy than the comfort mode. In the energy-saving mode, the average environmental data is as follows: Ambient temperature $28.3^{\circ} \mathrm{C}$, relative humidity $71.5 \%$, indoor wind speed $0.98 \mathrm{~m} / \mathrm{s}$, PMV 0.86 , and PPD $20.5 \%$, which is estimated to save $11.3 \%$ more energy than 
TABLE 8: Standards of control modes.

\begin{tabular}{lcccc}
\hline Mode & & & Item & \\
& Temperature & Wind speed & Relative humidity & Target PMV \\
\hline Comfortable & $26^{\circ} \mathrm{C}$ & $<0.5 \mathrm{~m} / \mathrm{s}$ & $50 \%$ & 0 \\
General & $27^{\circ} \mathrm{C}$ & $<0.5 \mathrm{~m} / \mathrm{s}$ & $60 \%$ & 0.5 \\
Energy-saving & $28^{\circ} \mathrm{C}$ & $<1 \mathrm{~m} / \mathrm{s}$ & $70 \%$ & 0.7 \\
\hline
\end{tabular}

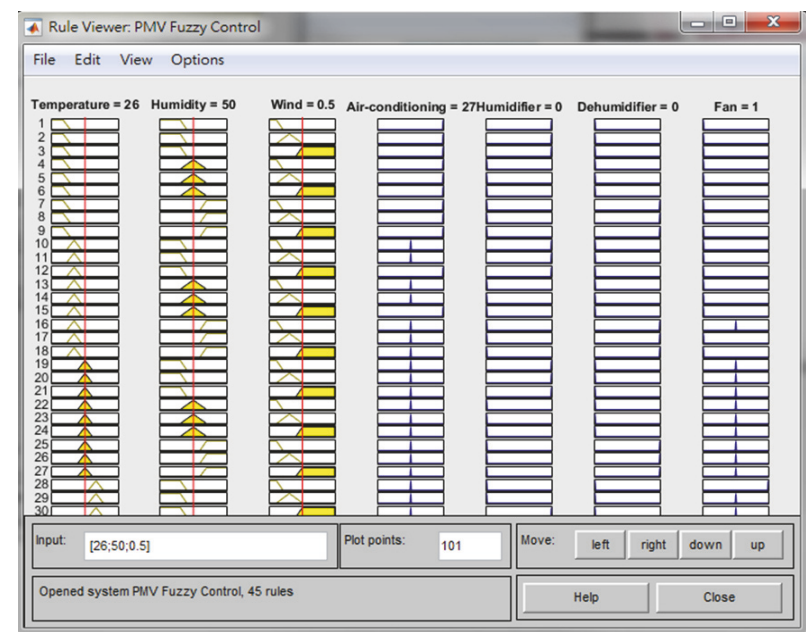

FIGURE 16: Fuzzy inference.

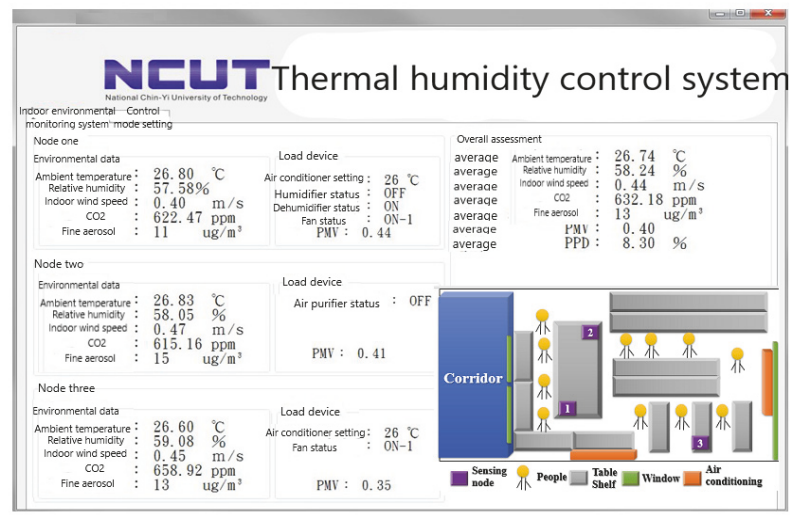

FIGURE 17: Main system monitoring interface.

the comfort mode. Figure 18 shows the experiment results of three control modes. Energy-saving data is based on the statistics of the Energy Bureau of the Ministry of Economic Affairs of Taiwan and the electrical power consumption of electrical appliances [8].

According to the experimental results in Figure 18, the energy-saving mode cannot completely reduce PMV to lower than 1 during the high temperature period at noon, as the cold air load cannot be accurately controlled to the decimal point according to the experimental observations due to control limitations. If the rule base is modified to reduce PMV at noon to be completely lower than 1 , the experimental data of Figure 19 will be obtained from the one-day experiment. When the temperature is lowered by $1^{\circ} \mathrm{C}$ near at noon, the control result approximate to that of the general mode will be obtained. As there is no wind speed limit, the average PMV is lower than that of the general mode; therefore, the original rule base is used as the control standard. According to the average environmental data of the three modes, the expected target PMV range can be achieved. The three thermal comfort control methods are still very effective and can balance thermal comfort and energy saving according to demand.

\section{Conclusion}

This paper mainly discusses the thermal comfort of people in an indoor environment under the system architecture of a wireless sensing network. Visual C\# software is used in the main console computer to design the man-machine monitoring interface, and the control model proposed in this 


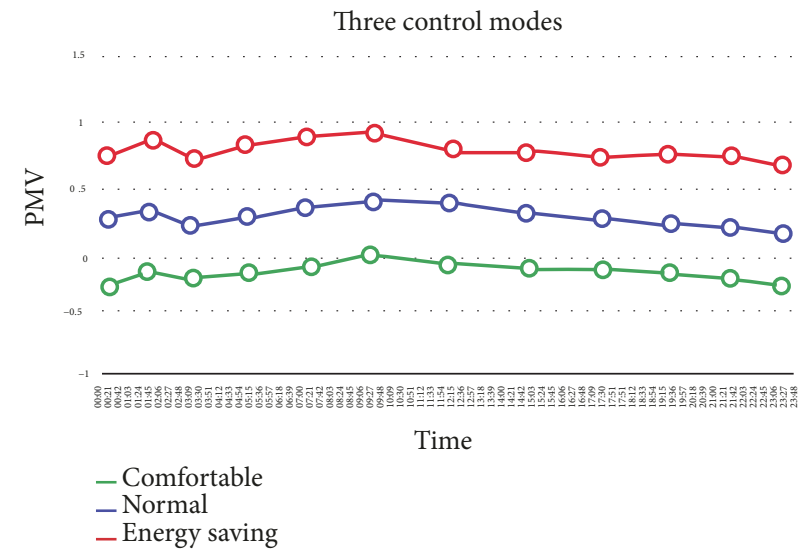

FIGURE 18: Comparison of three control modes.

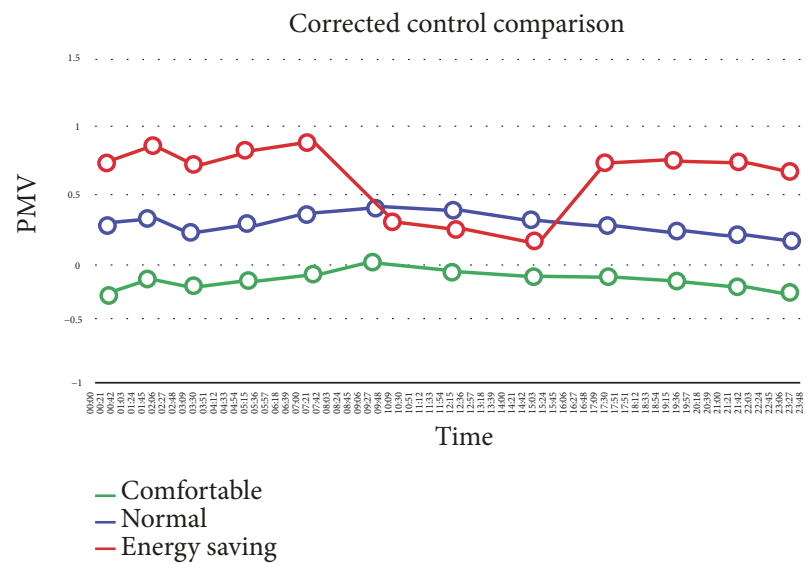

FIGURE 19: Comparison of control after modification.

study can be selected on the interface to control parameters such as temperature, humidity, and wind speed. Through MATLAB analysis and simulation of the indoor environment parameters that can be controlled, the effects of three controllable parameters such as ambient temperature, relative humidity, and indoor wind speed on the thermal comfort prediction index are obtained. The obtained data is used as the basis for the fuzzy control logic rule base. In order to control the load, people in the room have relatively better thermal comfort and make the energy use relatively better.

Our proposed system architecture is an IoT-based sensing network that emphasizes wireless transmission and rapid analysis of environmental parameters. This proposed method allows people in the room to be in a comfortable environment. In our research methods, there are still some improvements, such as network transmission problems, system processing and analysis capabilities, and infrared learning control problems in indoor electrical equipment.

\section{Data Availability}

All materials are publicly available.

\section{Conflicts of Interest}

The authors declare no conflicts of interest.

\section{References}

[1] W. T. Sung, S. J. Hsiao, and J. A. Shih, "Indoor thermal comfort environment monitoring system based on architecture of iot," in Proceedings of the 2018 International Symposium on Computer, Consumer and Control (IS3C), pp. 165-168, Taichung, Taiwan, December 2018

[2] X. B. Zho, The Application of Thermal Comfort Control Based on Smart [M. S. thesis], National Chin-Yi University of Technology, 2017.

[3] C. H. Chang, MATLAB Programming Design and Application, Winho Technology, 2000.

[4] K. T. Min, P. Lundrigan, and N. Patwari, "Demo abstract: IASA - Indoor air quality sensing and automation," in Proceedings of the 16th ACM/IEEE International Conference on Information Processing in Sensor Networks, IPSN 2017, pp. 277-278, USA, April 2017.

[5] N. H. Liu and Y. K. Chin, Building Thermal Environment, Tsinghua University Press, 2005.

[6] W. M. Shih, IOT Application and Development, Flag Technology, 2016.

[7] H. A. Chen, New Visual C\# Program Design Paradigm, Flag Technology, 3rd edition, 2014.

[8] J.-W. Chen and W.-C. Shao, "The indoor air quality of karaoke clubs hall and box," in Proceedings of the IEEE International 
Conference on Advanced Manufacturing (ICAM), pp. 338-341, 2018.

[9] S. Zhi, Y. Wei, Z. Cao, and C. Hou, "Intelligent controlling of indoor air quality based on remote monitoring platform by considering building environment," in Proceedings of the 4th International Conference on Systems and Informatics, ICSAI 2017, pp. 627-631, China, November 2017.

[10] ASHRAE, “Thermal Environment Conditions for Human Occupancy," ASHRAE Standard, vol. 55, 2010.

[11] C. Y. Chang, C. M. Weng, K. P. Shih, and W. H. Liao, Introduction to Internet of Things, Gotop Information, 2013.

[12] F. Wu, C. Rudiger, J.-M. Redoute, and M. R. Yuce, "WE-Safe: A wearable IoT sensor node for safety applications via LoRa," in Proceedings of the 4th IEEE World Forum on Internet of Things, WF-IoT 2018, pp. 144-148, Singapore, February 2018.

[13] R. N. Sogi, P. Chatterjee, U. Nethra, and V. Suma, "SMARISA: a raspberry Pi based smart ring for women safety using IoT," in Proceedings of the International Conference on Inventive Research in Computing Applications (ICIRCA), pp. 451-454, 2018.

[14] R. G. Steadman, "A universal scale of apparent temperature," Journal of Climate and Applied Meteorology, vol. 23, no. 12, pp. 1674-1687, 1984.

[15] A. P. Gagge, "An effective temperature scale based on a simple model of human physiological regulatory response," Ashrae Trans, pp. 21-36, 1971.

[16] P. O. Fanger, Thermal Comfort: Analysis and Applications in Environmental Engineering, McGraw-Hill, 1970.

[17] International Organization for Standardization, "Determination of the PMV and PPD indices and specification of the conditions for thermal comfort," ISO 7730:1994 Moderate thermal environments, 1994.

[18] International Organization for Standardization, "Analytical determination and interpretation of thermal comfort using calculation of the PMV and PPD indices and local thermal comfort criteria," ISO 7730:2005 Ergonomics of the Thermal Environment, 2005.

[19] International Organization for Standardization, "Estimation of thermal insulation and water vapor resistance of a clothing ensemble," ISO 9920:2007 Ergonomics of the Thermal Environment, 2007.

[20] International Organization for Standardization, "Determination of metabolic rate," ISO 8996:2004 Ergonomics of the Thermal Environment, 2004.

[21] R. P. Lai, "Discussion on the Building Ventilation in Taiwan," Chinese architect, pp. 17-33, 1980.

[22] A. V. Arundel, E. M. Sterling, J. H. Biggin, and T. D. Sterling, "Indirect health effects of relative humidity in indoor environments," Environmental Health Perspectives, vol. 65, pp. 351-361, 1986.

[23] W. C. Wang, Introduction to FUZZY, Chuan Hwa Publishing, 3rd edition, 2005.

[24] Z. Y. Sun and Y. K Yang, FUZZY: Theory, Practice and Application, Chuan Hwa Publishing, 1994.

[25] G. Mois, S. Folea, and T. Sanislav, "Analysis of three iotbased wireless sensors for environmental monitoring," IEEE Transactions on Instrumentation and Measurement, vol. 66, no. 8, pp. 2056-2064, 2017.

[26] F. Montori, L. Bedogni, and L. Bononi, "A collaborative internet of things architecture for smart cities and environmental monitoring," IEEE Internet of Things Journal, vol. 5, no. 2, pp. 592605, 2018. 


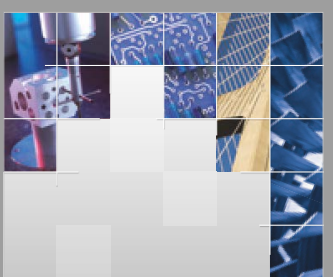

\section{Enfincering}
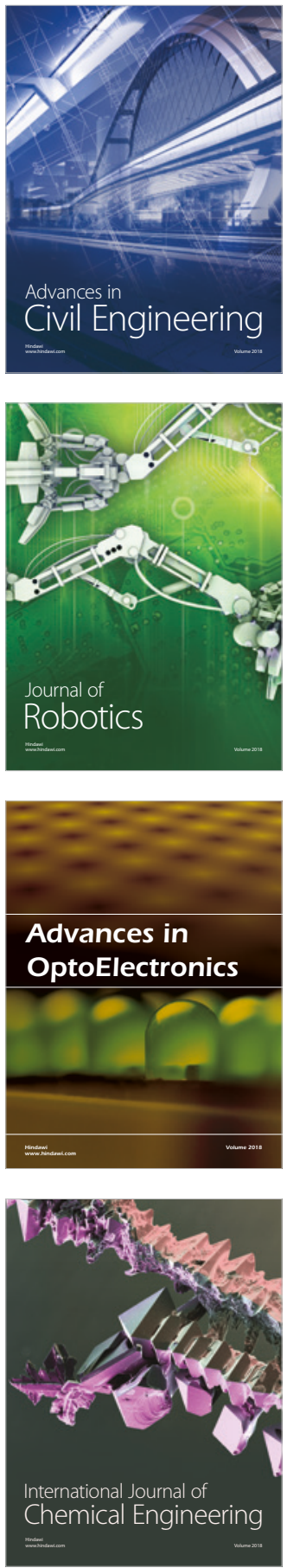

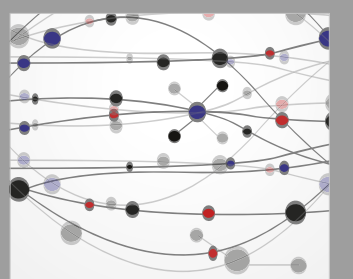

\section{Rotating \\ Machinery}

The Scientific World Journal

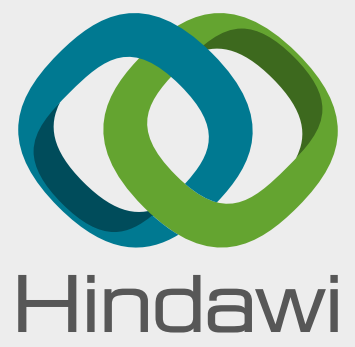

Submit your manuscripts at

www.hindawi.com
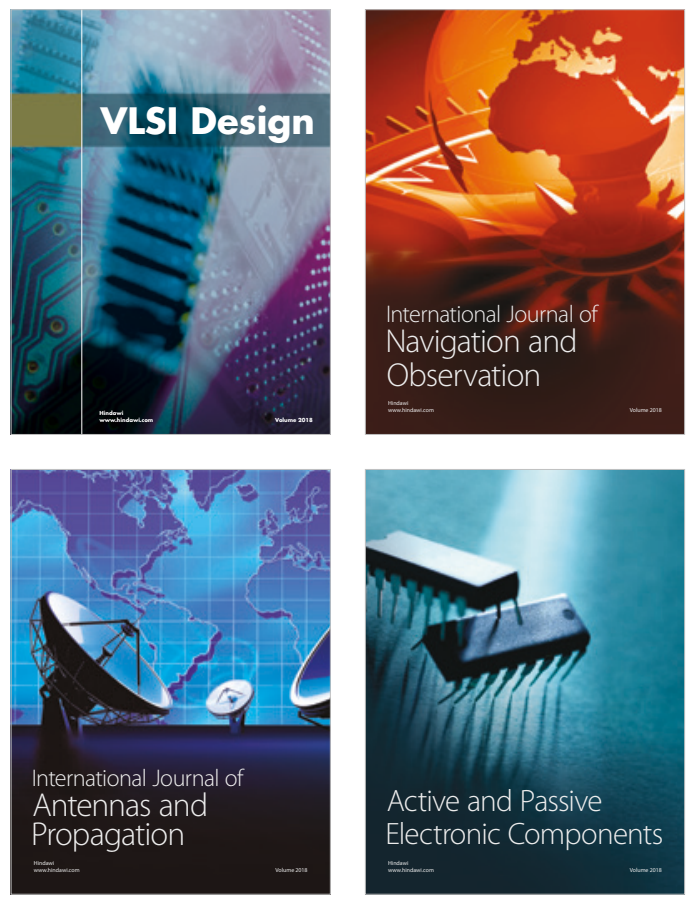
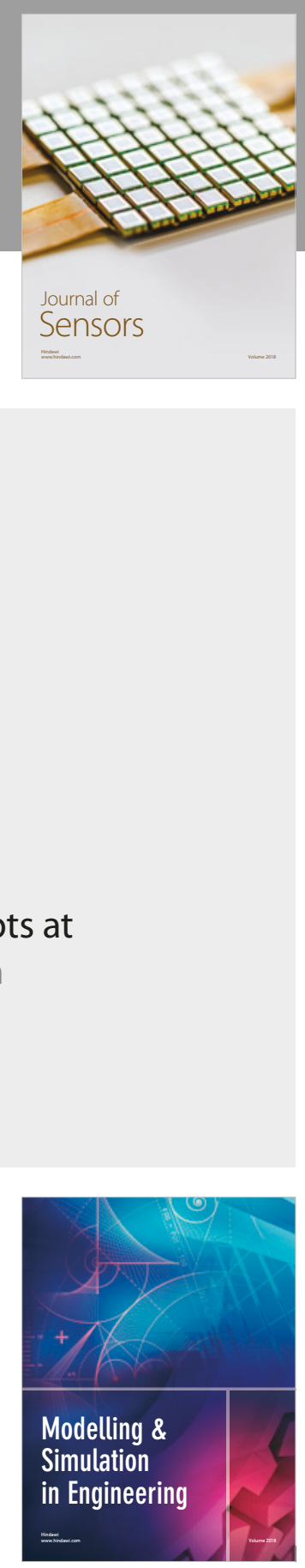

\section{Advances \\ Multimedia}
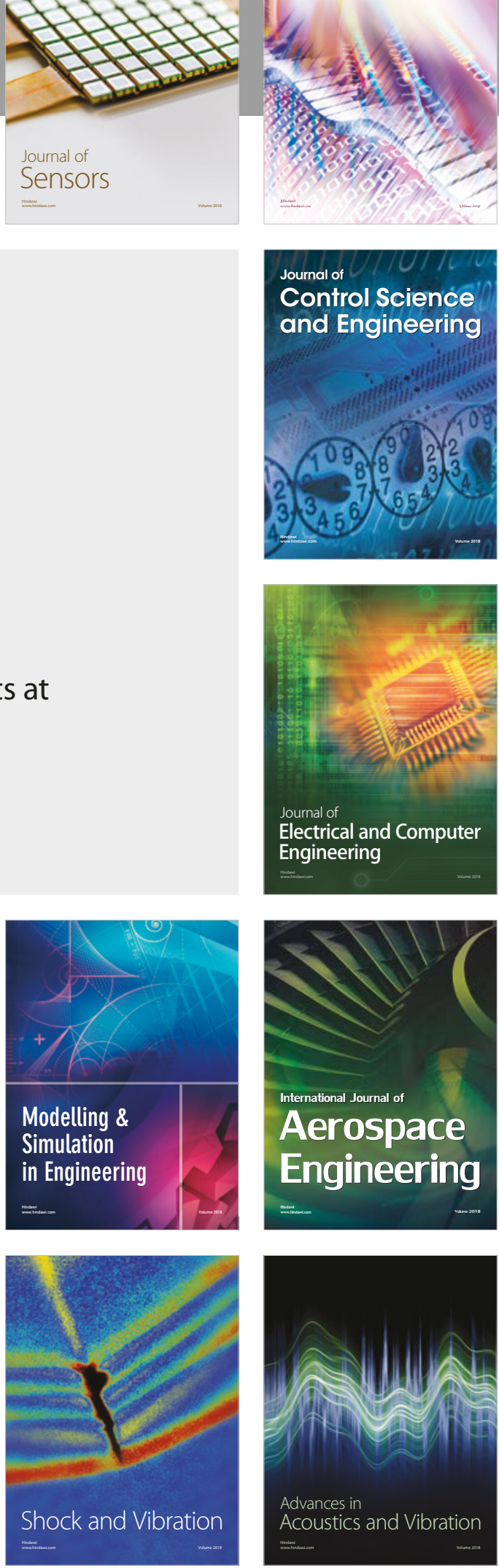